activities, and a steadily increasing recognition of its aims and objects by a wider public. Much more, however, remains to be done.

$$
\begin{aligned}
& \text { COURTAUld Thomsox, } \\
& \text { Chairman. } \\
& \text { JAMES LeATHAM Birley, } \\
& \text { Johx R. LORD, } \\
& \text { Joint Honorary Secretaries. }
\end{aligned}
$$

[Full copies of the Report, with several important appendices, can be obtained on application to the Secretary to the Council, Room 55, Windsor House, Victoria Street, Westminister.-EDs.]

\title{
MENTAL PROPHYLAXIS SERVICE OF THE SEINE DEPARTMENT, PARIS.
}

WE have received an interesting account from Dr. Edouard Toulouse, an Honorary Member of the Association since I90I, of the work in connection with the mental Clinic in the Seine district which was started in 1922 and has been organized on similar lines to the Maudsley Hospital. Dr. Toulouse, of Sainte Anne Asylum, is Director of the Clinic, which is, however, administratively independent of the asylum, and directly associated with the out-patient department of the Paris Medical School under the direction of Prof. Henri Claude. The Clinic has been opened and developed by the Council General of the Seine, thanks to the unfailing initiative of M. Henri Rouselle, President of the Commission for Assistance.

In the out-patient department patients are seen daily, and there are full facilities for medical and surgical examinations by specialists. The department is under the direction of the asylum and hospital physicians. The consultations are free, but are reserved for inhabitants of Paris and the Seine district. The work is growing rapidly; there are no less than 30 patients to be examined every day, and 8000 patients have been treated in the department. In connection with the clinic there are pathological laboratories affording full facilities for modern methods of biological investigation.

There are separate pavilions for men and women, and the wards contain dormitories for quiet patients, and rooms for those who need temporary isolation and for those who are placed under observation until medico-administrative decision has been adopted in regard to them; this decision cannot be taken until all tests and inquiries into the case have been made. An atmosphere of comfort and cheerfulness has been obtained, thanks to inexpensive contrivances, such as a tasteful selection of paintings and furniture, some of which are gifts, and arranged according to the advice of generous decorators and artists.

There is a Social Service Department, which is headed by the physicians, and functions through trained social workers. Supervision of the cases in the out-patient department and of former patients who have been discharged from the hospital is undertaken. This service undertakes, also, the ascertainment of psychopathic patients in the various city centres, schools and factories. A visiting system has been planned for patients who have been brought to the attention of the service but who cannot attend at the out-patient department. This part of the service is of considerable value, and becomes more necessary every day. Financial help is also afforded to the needy through the medium of the various charitable organizations. Dr. Toulouse points out that by means of this " open" clinic care and treatment is effected without restrictive measures. Its directing principle is the preservation of individual freedom, for legal measures are only used when it is found necessary after testing, observation, inquiries and reports of social workers. He anticipates that the number of legal commitments will be constantly diminishing with the development of clinics of this kind.

\section{EDUCATIONAL NOTES.}

The Maudsley Hospital, Denmark Hill, S.E. 5 (University of London).-Lectures and Practical Courses of Instruction (under the direction of Sir Frederick Mott) for a Diploma of Psychological Medicine. Course IX, 1926 